\title{
Efficacy and safety of dapsone gel for acne: a systematic review and meta-analysis
}

\author{
Xuesong Wang ${ }^{1}$, Zhenzhen Wang ${ }^{2,3}$, Lulu Sun ${ }^{2,3}$, Hong Liu ${ }^{2,3}$, Furen Zhang ${ }^{2,3}$ \\ ${ }^{1}$ First Clinical Medical College, Shandong University of Traditional Chinese Medicine, Jinan, China; ${ }^{2}$ Shandong Provincial Hospital for Skin \\ Diseases \& Shandong Provincial Institute of Dermatology and Veneorology, Jinan, China; ${ }^{3}$ Shandong First Medical University \& Shandong Academy \\ of Medical Sciences, Jinan, China \\ Contributions: (I) Conception and design: All authors; (II) Administrative support: H Liu, F Zhang; (III) Provision of study materials or patients: \\ X Wang, Z Wang, L Sun; (IV) Collection and assembly of data: X Wang, L Sun; (V) Data analysis and interpretation: X Wang, Z Wang; (VI) \\ Manuscript writing: All authors; (VII) Final approval of manuscript: All authors. \\ Correspondence to: Furen Zhang. Shandong Provincial Hospital for Skin Diseases, Shandong First Medical University, Jinan, China; \\ Shandong Provincial Institute of Dermatology and Venereology, Shandong Academy of Medical Sciences, 27397 Jingshi Road, Jinan, China. \\ Email: zhangfuren@hotmail.com.
}

\begin{abstract}
Background: First-line medications for acne vulgaris include retinoids and antibiotics. Dapsone is a topical drug approved by the U.S. Food and Drug Administration for the treatment of acne. However, due to its side effects, the clinical application of dapsone has not been promoted, and the value of the medication is still unclear. The aim of this study is to determine the efficacy and safety of dapsone gel in patients with acne.

Methods: Systematic searches were performed using the following databases on January 4, 2020: PubMed, EMBASE, Cochrane Central Register of Controlled Trials, China National Knowledge Infrastructure (CNKI), China Biomedical Literature Service System (SinoMed), China Science and Technology Journal Database (CQVIP), and Wanfang Data Knowledge Service Platform. A meta-analysis of randomized controlled trials was then conducted to analyze the efficacy and adverse events of dapsone gel treatment compared with excipient and other drug therapies. RevMan 5.3 software was used to calculate the odds ratio (OR), and the confidence interval (CI) was $95 \%$.

Results: Data of 11,424 participants across 7 trials which met the inclusion criteria were analyzed. Metaanalysis showed that dapsone gel alone or dapsone gel combined with isotretinoin was superior to excipient alone or oral isotretinoin alone in the treatment of acne $(\mathrm{OR}=1.51,95 \% \mathrm{CI}: 1.38-1.66, \mathrm{P}<0.0001$ random effects model, $\left.\mathrm{I}^{2}=0 \%\right)$. This indicates that dapsone gel is effective for the treatment of acne. We also found that dapsone gel is a more effective treatment for females (OR =1.80, 95\% CI: 1.46-2.23). There was no significant difference in the incidence of adverse events between the dapsone group and the control group (OR $=0.94$, 95\% CI: $0.82-1.14, \mathrm{P}=0.24$ random effects model; $\left.\mathrm{I}^{2}=29 \%\right)$. The common local adverse reactions in the dapsone group, such as dryness, heat, and eczema, were not statistically significant compared with those in the control group, and the side effects were transient.
\end{abstract}

Discussion: Dapsone gel is effective in treating acne, and there is no significant difference in adverse events compared with other drugs.

Keywords: Dapsone gel; acne; external application; systematic review

Submitted Nov 30, 2021. Accepted for publication Feb 11, 2022.

doi: 10.21037/apm-21-3935

View this article at: https://dx.doi.org/10.21037/apm-21-3935

$\wedge$ ORCID: 0000-0002-3436-6364. 


\section{Introduction}

Acne is a common chronic inflammatory skin disease of the hair follicle sebaceous glands (1). About $85 \%$ of adolescents suffer from acne, but adult acne is also becoming more common, especially in women $(1,2)$. The prevalence of acne in women is $12 \%$, while the prevalence in men is $3 \%$ (3). Acne often occurs at skin sites with a high density of sebaceous glands such as the face, chest, and back. As these common sites of occurrence can be quite visible, acne can lead to feelings of inferiority, anxiety, depression, social anxiety, and even suicidal tendencies (4).

Antibiotics and isotretinoin are frequently prescribed medications for acne. Antibiotics are prone to drug resistance while oral isotretinoin can cause adverse reactions and is contraindicated during pregnancy. Topical medications for acne include retinoic acid-like drugs, benzoyl peroxide, azelaic acid, and antibiotics for external use. These drugs can cause local irritation which can lead to skin redness, dryness, and exfoliation. Additionally, onetime use of these medications is not effective, and they often require combined medication $(5,6)$.

Sulfone is an old antibacterial and chemotherapeutic drug, and its antibacterial spectrum and mechanisms are similar to those of sulfonamide. However, it has no antibacterial activity against Gram-positive bacteria and Gram-negative bacteria, and has a strong direct inhibitory effect on Leprosy bacilli. In addition to treating various types of leprosy, it can also be used to treat bullous dermatosis, vasculitis dermatosis, aseptic pustulosis, and many intractable skin diseases such as chronic urticaria, oral mucosal ulcers, and non-scar chronic lupus erythematosus damage $(7,8)$. Dapsone is a sulfone with anti-inflammatory and anti-microbial properties. However, efforts to develop topical treatments of dapsone have been hampered by its poor solubility in water carriers typically used in dermatology products. In recent years, a hydrogel has been produced such that a clinically effective dose of dapsone can be used locally with minimal systemic absorption. In this way, dapsone gel can be successfully used in clinical practice. Both $5 \%$ and $7.5 \%$ dapsone gels were approved by the FDA in 2008 and 2017, respectively, for clinical indications including acne $(9,10)$. This study finds that the application of dapsone gel can effectively mitigate the drug resistance of acne and can be used as a substitute for isotretinoin and antibiotics. We present the following article in accordance with the PRISMA reporting checklist (available at https://apm.amegroups.com/article/view/10.21037/apm$21-3935 / \mathrm{rc})$.

\section{Methods}

\section{Literature retrieval strategy}

The review protocol of this study was registered in the PROSPERO database prior to initiating the review process (CRD42020180236). This study was conducted in accordance with the Cochrane Handbook for Systematic Reviews of Interventions.

Prior to January 4, 2020, we searched the following 6 databases: PubMed, Cochrane Central Register of Controlled Trials, EMBASE, China Biomedical Literature Service System (SinoMed), China National Knowledge Infrastructure (CNKI), China Science and Technology Journal Database (CQVIP), and Wanfang Data Knowledge Service Platform. Randomized controlled trials (RCTs) were selected to evaluate the safety and effectiveness of dapsone gel in treating acne. Search terms included "dapsone", "dapsone gel", and "acne".

\section{Inclusion and exclusion criteria}

The acne treatment method involved dapsone alone or in combination with traditional medicines. The results of these trials were compared with either a placebo or with traditional medications. Trials were excluded from this study if any of the following factors were found: (I) non-RCTs, (II) review studies, (III) lack of information on research results, (IV) animal trials, (V) lack of dapsone treatment. The Global Acne Assessment Score (GAAS) sheet was used to assess the classification of acne. When the patient's score was "none" [0] or "lowest" [1] in the 5-point static scoring system, the treatment was successful.

\section{Literature screening and data extraction}

Relevant RCTs were chosen according to the above inclusion criteria, and then the results were independently screened by reviewers Xuesong Wang and Zhenzhen Wang. One reviewer, Xuesong Wang, extracted data from the included trials and evaluated the risk of bias in the included RCTs using the Cochrane Collaboration's tool for assessing the risk of bias. The other reviewer, Zhenzhen Wang, verified the extracted data and assessed the risk of bias. The differences were then analyzed by a third author, Lulu Sun.

\section{Risk of bias}

The bias risk for each study was calculated according 


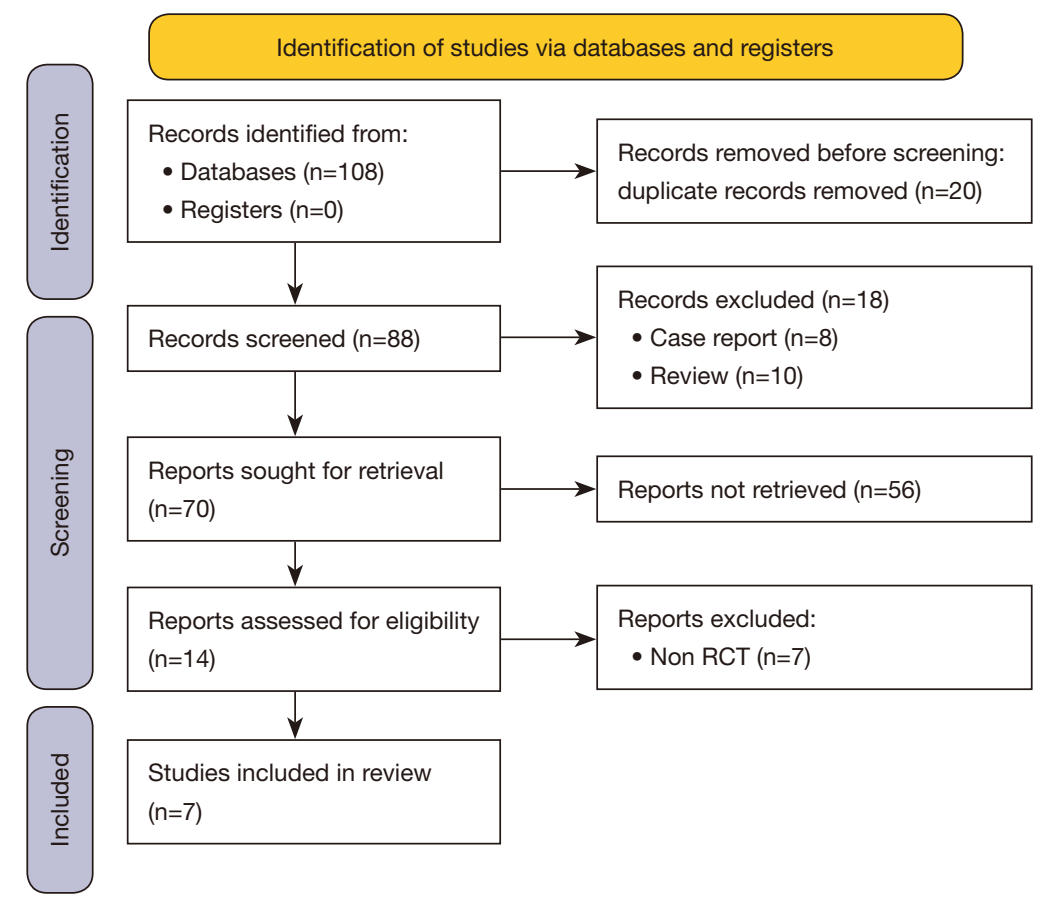

Figure 1 Flowchart depicting study selection. RCT, randomized controlled trial.

to the Cochrane Handbook for Systematic Reviews of Interventions. The following 6 criteria were applied: (I) selection bias (random sequence generation and allocation concealment), (II) performance bias (blinding participants and personnel), (III) detection bias (blinding in the evaluation of results), (IV) attrition bias (incomplete outcome data), (V) reporting bias (selective reporting), (VI) other bias. According to the above criteria, the included research was divided into low risk, high risk, and unclear risk. When the reported methods and result details were insufficient, or when the indicators were not related to the study, the bias risk was unknown. In such cases, the study was rated as having unclear risk.

\section{Statistical analysis}

Dichotomous data are expressed as an odds ratio (OR) with a $95 \%$ confidence interval (CI). Continuous data are represented by mean difference (MD), and the confidence interval is $95 \%$. Statistical heterogeneity tests were carried out for the 7 experiments. RevMan 5.3 software, provided by the Cochrane Collaboration, was utilized for data analysis. A meta-analysis was performed to determine if the trial had acceptable homogeneity $\left(\mathrm{I}^{2}<85 \%\right)$ in terms of study design, participants, interventions, controls, and outcome measures. In the study of homogeneity, the fixed effects model $\left(\mathrm{I}^{2}<25 \%\right)$ and heterogeneity $\left(25 \%<\mathrm{I}^{2}<85 \%\right)$ were used before the random effects model. In order to explore the possible causes of heterogeneity, we used a meta-analysis of predefined variables and the random effects model for subgroup analysis.

\section{Results}

\section{Included studies and their characteristics}

After a preliminary search of 8 databases, 108 citations were identified. After reading their titles and abstracts, 101 of these studies were excluded as they did not meet the inclusion criteria. The remaining 7 studies (11-17) that met the inclusion criteria were then read in full, and all 7 studies consisting of 11,424 participants were ultimately included in this analysis (Figure 1). The characteristics of the included studies are shown in Table 1.

The graph describing the risk of bias is shown in Figure 2 . All of the included studies reported randomization, and 6 of the studies fully described their randomization methods (11,14-16). Four studies $(11,14,16,17)$ reported using computerization methods, 2 studies $(12,15)$ used interactive voice/network randomization system methods (provided by 
Table 1 Characteristics of the included studies

\begin{tabular}{|c|c|c|c|c|c|}
\hline Author & Year & Sample size $(\mathrm{I} / \mathrm{C})$ & Interventions (I/C) & $\begin{array}{l}\text { Course of } \\
\text { treatment (weeks) }\end{array}$ & $\begin{array}{l}\text { Used } \\
\text { instruments }\end{array}$ \\
\hline Tanghetti $E(11)$ & 2011 & $86 / 85$ & $\begin{array}{l}\text { Dapsone gel } 5 \% \text { twice-daily plus tazarotene cream } 0.1 \% \\
\text { daily/tazarotene cream } 0.1 \% \text { daily }\end{array}$ & 12 & GAAS \\
\hline Raimer S (12) & 2008 & $578 / 547$ & Twice-daily $5 \%$ dapsone gel/vehicle gel twice-daily & 12 & GAAS \\
\hline Stein Gold LF (13) & 2016 & $948 / 976$ & $\begin{array}{l}\text { Topical dapsone gel, } 7.5 \% \text { once daily/vehicle gel once- } \\
\text { daily }\end{array}$ & 12 & GAAS \\
\hline Draelos ZD (14) & 2007 & $1,506 / 1,504$ & $5 \%$ dapsone gel twice-daily/vehicle gel twice-daily & 12 & GAAS \\
\hline Tanghetti E (15) & 2012 & $1,453 / 1,445$ & $5 \%$ dapsone gel twice daily/vehicle twice daily & 12 & GAAS \\
\hline Eichenfield LF (16) & 2016 & $1,118 / 1,120$ & Once-daily dapsone $7.5 \% \mathrm{gel} /$ vehicle gel once-daily & 12 & GAAS \\
\hline Faghihi G (17) & 2014 & $29 / 29$ & $\begin{array}{l}\text { Oral isotretinoin } 20 \mathrm{mg} \text { daily and topical } 5 \% \text { dapsone gel } \\
\text { twice a day/oral isotretinoin } 20 \mathrm{mg} \text { daily and topical vehicle } \\
\text { gel twice a day }\end{array}$ & 12 & GAAS \\
\hline
\end{tabular}

I, intervention group; C, control group; GAAS, Global Acne Assessment Score.

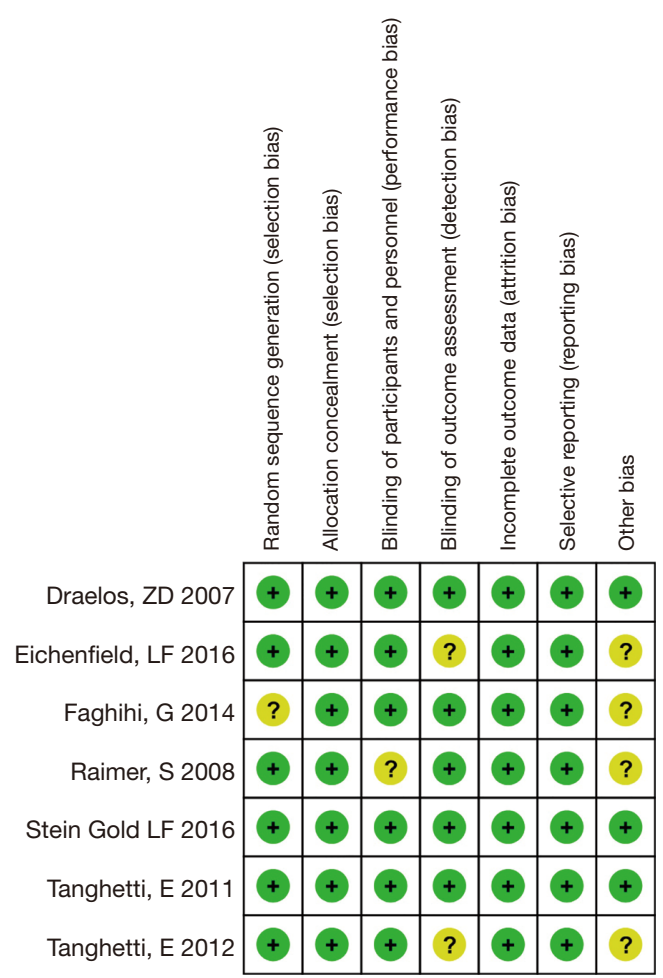

Figure 2 Risk of bias summary. the sponsor), and 1 study (13) did not mention any specific randomization methods.

There was no detailed evaluation method described for the results of the first study (11), nor was there mention of the methodology used in the drug implementation process in the third study (14). One study (13) was biased and could not compare the number of people showing effective results. All the trials adequately addressed selective reporting bias. We found no other bias in these trials. However, 4 studies (12,14-16) had unknown risk, and we decided that all included trials need pay attention to the risk of unclear bias. Additionally, since the data used in 2 studies $(11,17)$ were from the same clinical trial, the data provided in study 7 were analyzed separately and not included in the efficacy evaluation analysis or adverse event analysis $(11,17)$.

\section{Meta-analysis results}

\section{Effects of dapsone gel versus vehicle gel}

Five studies $(11,12,14-16)$ compared dapsone gel with vehicle gel. Comparing the number of successful cases using dapsone gel with cases using an excipient, the difference was statistically significant $(\mathrm{OR}=1.52,95 \% \mathrm{CI}$ : $\left.1.39-1.67, \mathrm{P}=0.63, \mathrm{I}^{2}=0 \%\right)$. This shows that the curative 


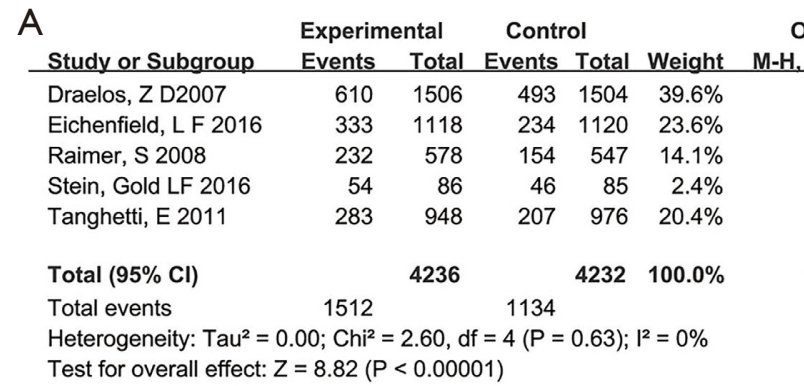

B

\begin{tabular}{|c|c|c|c|c|c|}
\hline \multirow[b]{2}{*}{ Study or Subgroup } & \multicolumn{2}{|c|}{ Experimental } & \multicolumn{2}{|c|}{ Control } & \multirow[b]{2}{*}{ Weight } \\
\hline & Events & Total & Events & Total & \\
\hline Tanghetti, E 2011 & 54 & 86 & 46 & 85 & $100.0 \%$ \\
\hline Total $(95 \% \mathrm{Cl})$ & & 86 & & 85 & $100.0 \%$ \\
\hline Total events & 54 & & 46 & & \\
\hline
\end{tabular}

Odds Ratio

Odds Ratio

Random, $95 \% \mathrm{Cl}$ M-H, Random, $95 \% \mathrm{Cl}$

$1.40[1.20,1.62]$

$1.61[1.32,1.95]$

$1.71[1.33,2.20]$

$1.43[0.78,2.64]$

$1.58[1.29,1.94]$

$1.52[1.39,1.67]$

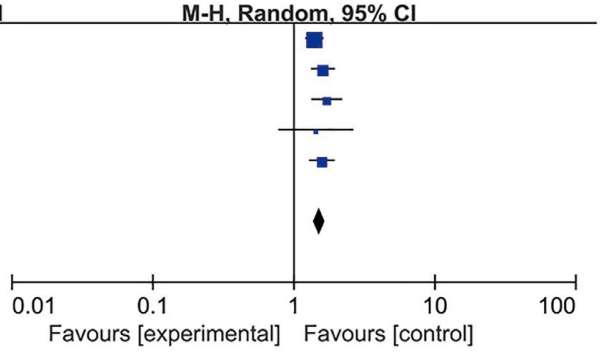

Odds Ratio Odds Ratio M-H, Random, $95 \%$ Cl

$1.43[0.78,2.64]$

$1.43[0.78,2.64]$

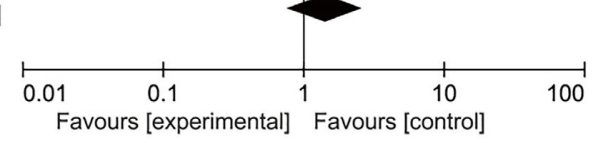

C

\begin{tabular}{|c|c|c|c|c|c|c|c|c|c|c|}
\hline Study or Subgroup & $\begin{array}{l}\text { femal } \\
\text { Events }\end{array}$ & Total & $\begin{array}{l}\text { male } \\
\text { Events }\end{array}$ & Total & Weight & $\begin{array}{l}\text { Odds Ratio } \\
\text { M-H, Random, } 95 \% \mathrm{Cl}\end{array}$ & & $\begin{array}{r}\text { Odds } \\
\text { M-H, Randc }\end{array}$ & $\begin{array}{l}\text { Ratio } \\
\text { lom, } 95 \% \mathrm{Cl}\end{array}$ & \\
\hline Tanghetti, E 2012 & 366 & 753 & 241 & 700 & $100.0 \%$ & $1.80[1.46,2.23]$ & & & & \\
\hline Total $(95 \% \mathrm{Cl})$ & & 753 & & 700 & $100.0 \%$ & $1.80[1.46,2.23]$ & & & & \\
\hline Total events & 366 & & 241 & & & & & & & \\
\hline \multicolumn{7}{|c|}{$\begin{array}{l}\text { Heterogeneity: Not applicable } \\
\text { Test for overall effect: } Z=5.45(P<0.00001)\end{array}$} & 0.01 & ${ }_{\text {Favours [famale] }}^{0.1}$ & $1 \frac{10}{\text { Favours [male] }}$ & 100 \\
\hline
\end{tabular}

Figure 3 Meta-analysis of the efficacy of different therapies for acne treatment and the effect of gender on efficacy. (A) Dapsone gel for acne versus other therapies. (B) Dapsone gel vs. tazarotene. (C) The efficacy of dapsone $5 \%$ gel in female $v s$. male patients with acne.

effect of dapsone gel is better than that of the control group (Figure $3 A$ ).

One study (16) observed the therapeutic effects of dapsone gel paired with tazarotene cream $(\mathrm{OR}=1.43,95 \%$ CI: 0.78-2.64, $\mathrm{P}=0.25$ ) (Figure 3B). The results showed that tazarotene cream used alongside dapsone gel had no obvious effect on the treatment of acne vulgaris compared with the use of tazarotene cream alone. One study (17) observed the effects of dapsone gel on each gender. The results showed that dapsone gel was significantly more effective for treating acne in women than in men (OR $=1.80,95 \%$ CI: $1.46-2.23$, $\mathrm{P}<0.00001$ ) (Figure 3C).

\section{Adverse events}

All adverse events were mild. Three studies $(11,12,15)$ stated the incidence of overall adverse events. There was no significant difference in the incidence of adverse events between dapsone gel and excipient gel $[\mathrm{OR}=0.94,95 \% \mathrm{CI}$ : $0.82-1.08, \mathrm{P}=0.37$ random effects model, $\mathrm{I}^{2}=29 \%$ ] (Figure 4).

Six studies (11-16) analyzed local skin dryness $(\mathrm{OR}=1.10$,
95\% CI: $0.95-1.28, \mathrm{P}=0.20$ random effects model, $\left.\mathrm{I}^{2}=0 \%\right)$ (Figure 5A). Five studies (11,13-16) analyzed local skin erythema $(\mathrm{OR}=0.97,95 \% \mathrm{CI}$ : $0.81-1.17, \mathrm{P}=0.78$ random effects model, $\mathrm{I}^{2}=4 \%$ ) (Figure $5 B$ ). In 2 studies $(11,13)$, the incidence of a local burning sensation was statistically analyzed (OR $=1.59,95 \%$ CI: $\left.0.35-7.19, \mathrm{P}=0.55, \mathrm{I}^{2}=68 \%\right)$ (Figure 5C). Four studies(11-13,15), the incidence of local Pruritus was statistically analyzed $(\mathrm{OR}=1.17,95 \% \mathrm{CI}$ : $0.70-1.98, \mathrm{P}=0.55, \mathrm{I}^{2}=11 \%$ ) (Figure $\left.5 D\right)$. In 2 studies $(12,15)$, the condition of local skin pain was statistically analyzed (OR $=0.32,95 \%$ CI: $0.16-0.63, \mathrm{P}=0.001, \mathrm{I}^{2}=44 \%$ ) (Figure $5 E$ ). Four studies $(11,12,14,15)$ analyzed patients with rhinitis $\left(\mathrm{OR}=0.81,95 \%\right.$ CI: $\left.0.65-1.01, \mathrm{P}=0.06, \mathrm{I}^{2}=0 \%\right)$ (Figure 6 A), and another 4 studies $(11,12,14,15)$ analyzed patients with headache $\left(\mathrm{OR}=1.11,95 \% \mathrm{CI}: 0.84-1.48, \mathrm{P}=0.46, \mathrm{I}^{2}=1 \%\right)$ (Figure 6B). Three studies $(11,12,15)$ analyzed patients with symptoms of upper respiratory tract infection $(\mathrm{OR}=1.04$, 95\% CI: 0.76-1.44, $\mathrm{P}=0.79, \mathrm{I}^{2}=0 \%$ ) (Figure 6C). Two studies $(11,15)$ analyzed patients with pharyngitis $(\mathrm{OR}=1.00,95 \%$ CI: $0.67-1.51, \mathrm{P}=0.99, \mathrm{I}^{2}=0 \%$ ) (Figure $6 D$ ). 


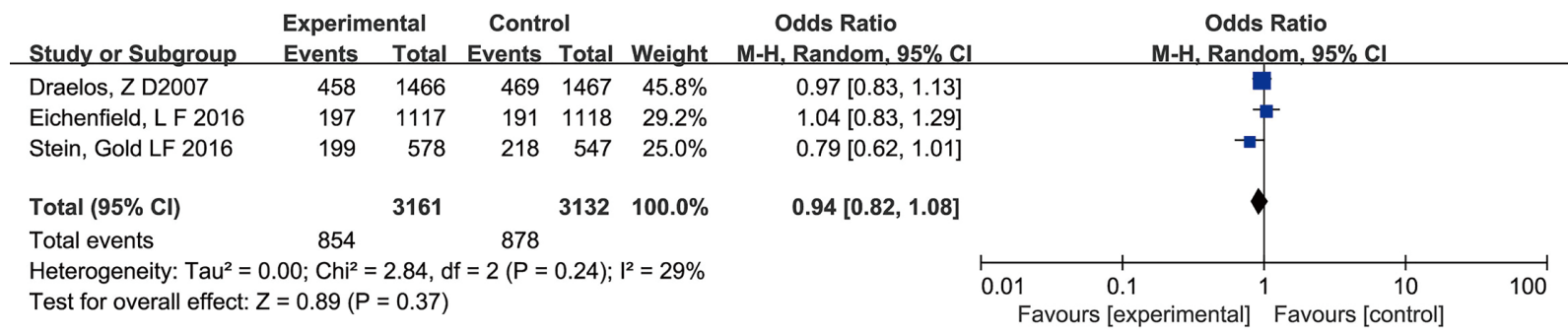

Figure 4 Meta-analysis of the adverse event rates between the dapsone gel treatment group and other therapies.

The results of this meta-analysis show that the incidence of adverse events is not significantly different between dapsone gel or excipient. The dry skin, erythema, and burning sensation produced by the external application of the gel were also not significantly different between groups according to the meta-analysis. The symptoms of local skin pain appeared more in the excipient group. The comparison of adverse events other than local symptoms was not statistically significant.

\section{Discussion}

Through this meta-analysis of 7 studies, it can be seen that in regard to the treatment of acne vulgaris, dapsone gel alone or in combination with other drug therapies has a higher success rate than excipients or oral isotretinoin. The success rate of dapsone gel in treating acne is even higher in female patients (17). There is no clear explanation for these results, and there has yet to be research showing the interaction between sex hormones and dapsone. It is worth noting that the combination of dapsone gel and tazarotene gel did not show a superior therapeutic effect compared with tazarotene alone. However, there has yet to be a study showing the pharmacological reactions between dapsone and tazarotene. The sample size of this study is small, and the clinical effect of dapsone gel combined with other topical drugs remains to be seen. The common side effects are dryness, erythema, and burning sensation, along with systemic symptoms such as rhinitis, pharyngitis, upper respiratory tract infection, and headache during treatment. However, the occurrence of these adverse events was not statistically significant according to our meta-analysis, indicating that the use of dapsone gel is safe and effective.

Acne is a multifactorial inflammatory disease. Aside from antibiotics, benzoyl peroxide, and retinoic acid, there have been few topical drugs which have been proposed and comprehensively studied for the treatment of acne (18).
Dapsone has anti-inflammatory and antibacterial effects, and is used to treat leprosy and rare skin diseases. Studies have shown that dapsone gel is a more effective treatment for inflammatory acne than it is for non-inflammatory acne. However, oral administration of dapsone can lead to serious complications such as dapsone syndrome and high hemolysis risk in patients with G6PD deficiency, along with other adverse effects. In order to study the safety of dapsone gel, Piette $e t$ al. chose a group of patients with G6PD deficiency to conduct an RCT (19). A hematological examination revealed that dapsone gel is safe for use on patients with G6PD deficiency. Despite the relatively low external absorption quantity of dapsone gel, there are still reports of adverse reactions caused by topical dapsone gel use. Yale $e t$ al. reported a case in which an adolescent girl experienced serious methemoglobinemia after topical use of $5 \%$ dapsone gel (20). This means dapsone gel is safe for external use.

This study verifies that dapsone gel is an appropriate choice for acne treatment and a good substitute for topical antibiotics and isotretinoin, but our meta-analysis also has some limitations. For example, these studies lack significant racial diversity in participating patients, and there was only one Asian article with a small sample size. Thus, there is still a lack of research on whether dapsone gel use shows differences in efficacy among different racial groups. Due to inconsistent statistical methods between the studies analyzed, baseline data could not be included in the meta-analysis. This results in a lack of data integrity for the evaluation of treatment effects. There was also little comparison between traditional drugs for acne vulgaris, such as benzoyl peroxide and vitamin A acid, and there was no comparison at all between dapsone gel and these traditional medicines. Although the long-term use of antimicrobial agents will inevitably affect the normal flora of the skin. However, at present, there are no reports of dapsone causing this situation, but this is worthy of our vigilance, especially for patients with long-term use. There 
A

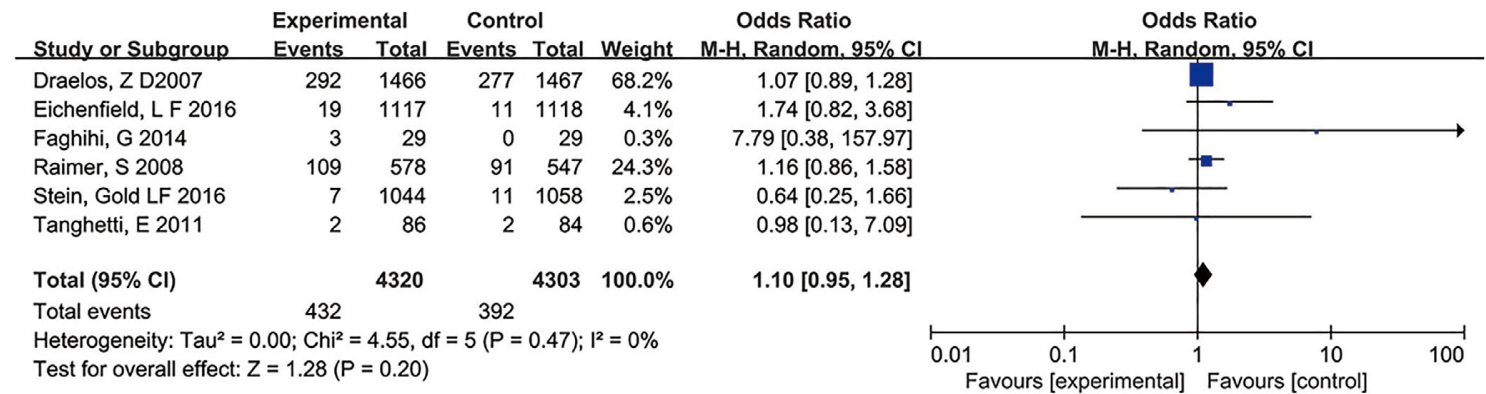

B

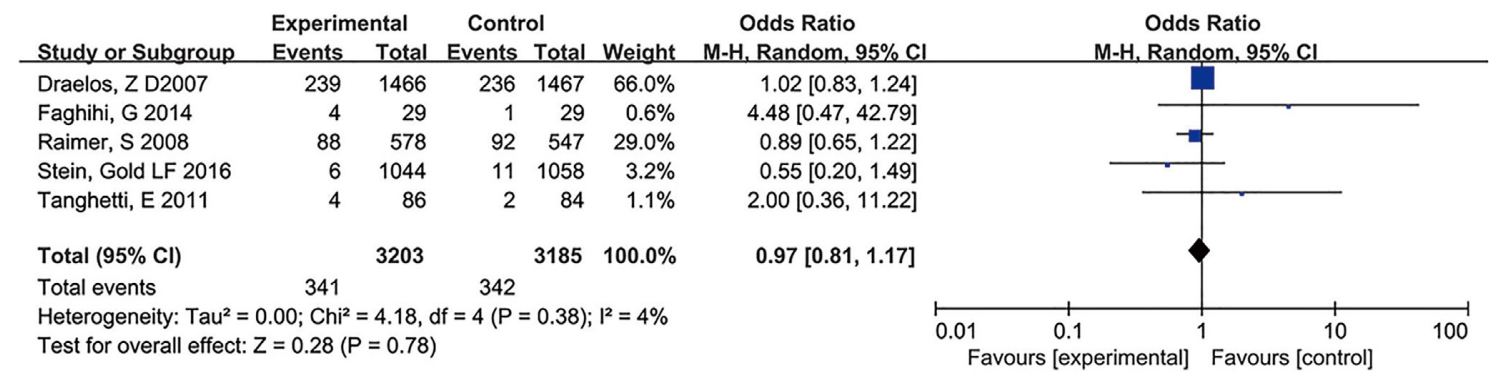

C

Odds Ratio

M-H. Random. $95 \% \mathrm{Cl}$

\begin{tabular}{|c|c|c|c|c|c|}
\hline \multirow[b]{2}{*}{ Study or Subgroup } & \multicolumn{2}{|c|}{ Experimental } & \multicolumn{2}{|c|}{ Control } & \multirow[b]{2}{*}{ Weight } \\
\hline & Events & Total & Events & Total & \\
\hline Draelos, Z D2007 & 22 & 1466 & 25 & 1467 & $62.6 \%$ \\
\hline Faghihi, G 2014 & 7 & 29 & 2 & 29 & $37.4 \%$ \\
\hline Total $(95 \% \mathrm{Cl})$ & & 1495 & & 1496 & $100.0 \%$ \\
\hline Total events & 29 & & 27 & & \\
\hline Heterogeneity: $\mathrm{Tau}^{2}$ & $.86 ; \mathrm{Chi}^{2}$ & $=3.11, d$ & $f=1(P=$ & $=0.08)$ & $;\left.\right|^{2}=68$ \\
\hline
\end{tabular}

Test for overall effect: $Z=0.60(P=0.55)$

$0.88[0.49,1.57]$

$4.30[0.81,22.80]$

$1.59[0.35,7.19]$

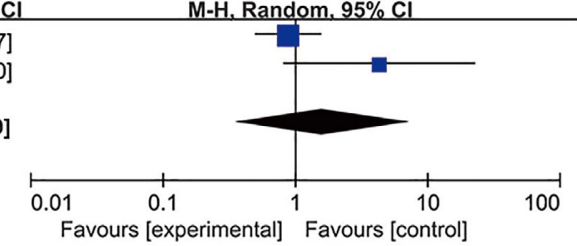

Odds Ratio

Odds Ratio

Study or Subgroup Events Total Events Total Weight M-H. Random, 95\% Cl

$\begin{array}{lllllll}\text { Draelos, Z D2007 } & 14 & 1466 & 19 & 1467 & 44.4 \% & 0.73[0.37,1.47]\end{array}$

$\begin{array}{lllllll}\text { Eichenfield, L F } 2016 & 12 & 1117 & 6 & 1118 & 24.8 \% & 2.01[0.75,5.38\end{array}$

$\begin{array}{llllll}\text { Faghihi, G } 2014 & 1 & 29 & 0 & 29 & 2.6 \%\end{array}$

$\begin{array}{llllll}\text { Stein, Gold LF } 2016 & 11 & 1044 & 8 & 1058 & 28.2 \%\end{array}$

Total $(95 \% \mathrm{Cl})$

$\begin{array}{lll}\text { Total events } & 38 & 33 \\ \text { Heterogeneity: } \text { Tau }^{2}=0.03 ; \mathrm{Chi}^{2}=3.38, \mathrm{df}=3(P=0.34) ; \mathrm{l}^{2}=11 \%\end{array}$

3656

Test for overall effect: $Z=0.60(P=0.55)$

$3.11[0.12,79.43]$

$1.40[0.56,3.49]$

$1.17[0.70,1.98]$

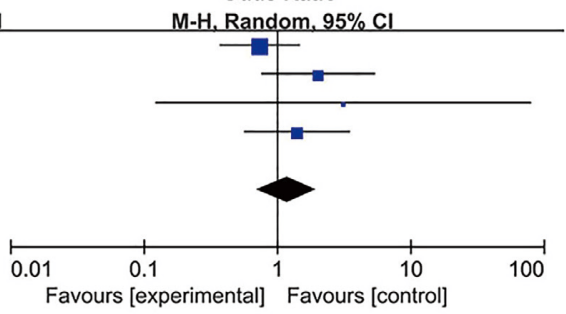

Odds Ratio

Odds Ratio

\begin{tabular}{|c|c|c|c|c|c|}
\hline & Experim & ntal & Cont & & \\
\hline Study or Subgroup & Events & Total & Events & Total & Weight \\
\hline Eichenfield, LF 2016 & 9 & 1117 & 19 & 1058 & $58.2 \%$ \\
\hline Stein, Gold LF 2016 & 2 & 1044 & 14 & 1058 & $41.8 \%$ \\
\hline Total $(95 \% \mathrm{Cl})$ & & 2161 & & 2116 & $100.0 \%$ \\
\hline Total events & 11 & & 33 & & \\
\hline $\begin{array}{l}\text { Heterogeneity: } \mathrm{Ch}^{2}= \\
\text { Test for overall effect: }\end{array}$ & $\begin{array}{l}78, d f=1 \\
=3.26(P\end{array}$ & $\begin{array}{l}P=0.1 \\
=0.001\end{array}$ & $3) ; 1^{2}=4$ & & \\
\hline
\end{tabular}

M-H, Fixed, $95 \% \mathrm{Cl}$

$0.44[0.20,0.99]$

$0.14[0.03,0.63]$

$0.32[0.16,0.63]$

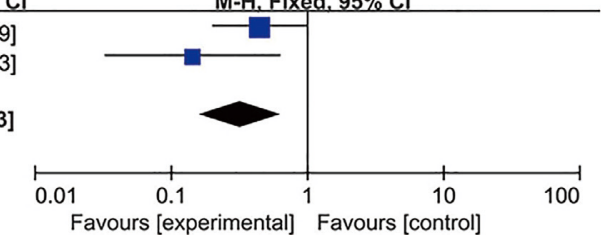

Figure 5 Meta-analysis of adverse symptoms at the site of medication. (A) Dryness, (B) erythema, (C) burning, (D) pruritus, (E) pain. 


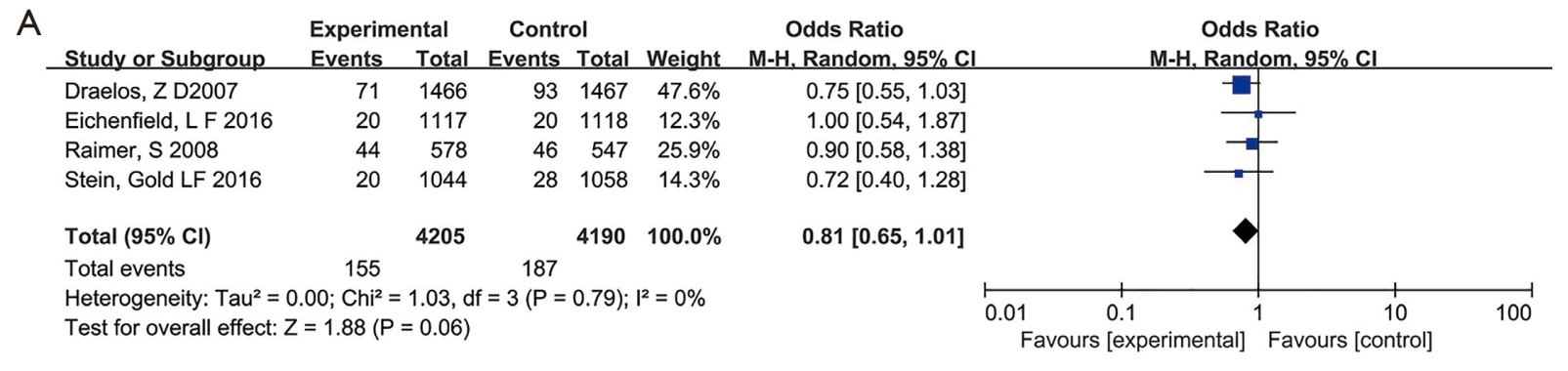

\section{B}

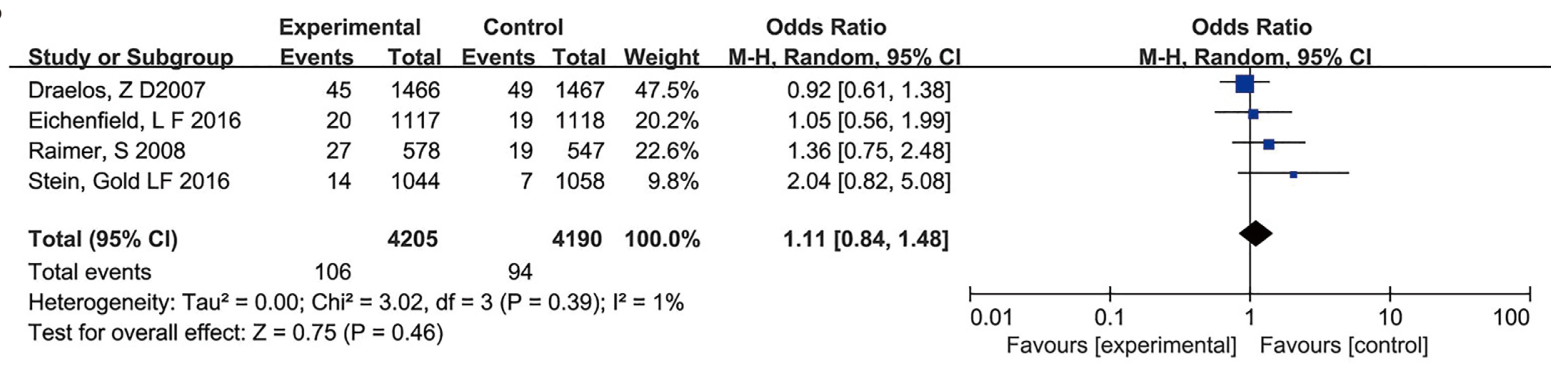

C

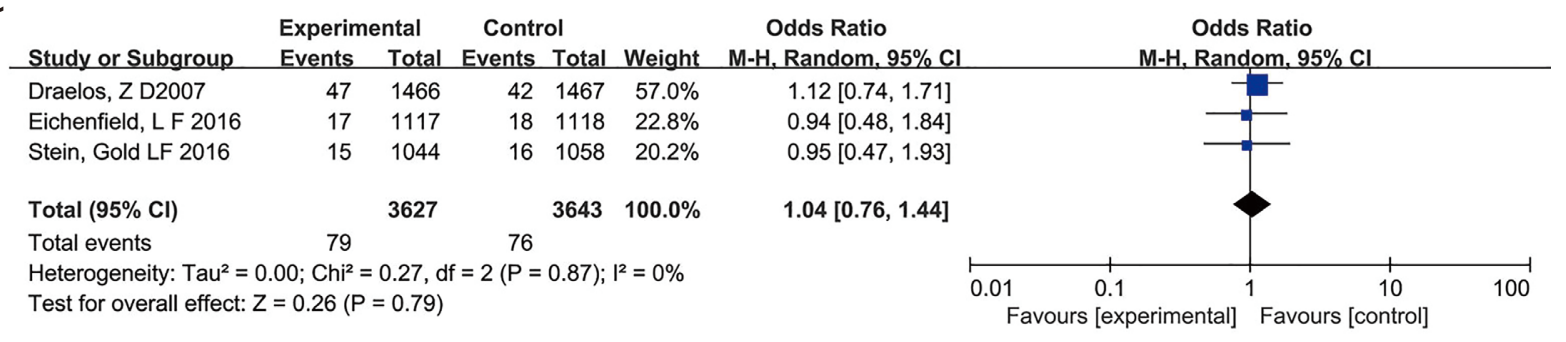

\begin{tabular}{|c|c|c|c|c|c|}
\hline \multirow[b]{2}{*}{ Study or Subgroup } & \multicolumn{2}{|c|}{ Experimental } & \multicolumn{2}{|c|}{ Control } & \multirow[b]{2}{*}{ Weight } \\
\hline & Events & Total & Events & Total & \\
\hline Draelos, Z D2007 & 37 & 1466 & 38 & 1467 & $79.6 \%$ \\
\hline Stein, Gold LF 2016 & 10 & 1044 & 9 & 1058 & $20.4 \%$ \\
\hline Total $(95 \% \mathrm{Cl})$ & & 2510 & & 2525 & $100.0 \%$ \\
\hline $\begin{array}{l}\text { Total events } \\
\text { Heterogeneity: } \text { Tau }^{2}= \\
\text { Test for overall effect }\end{array}$ & $\begin{array}{c}47 \\
.00 ; \mathrm{Chi}^{2} \\
=0.02(\mathrm{P}\end{array}$ & $0.08, d$ & If $=1$ 1 $1(P=$ & & \\
\hline
\end{tabular}

Odds Ratio Odds Ratio

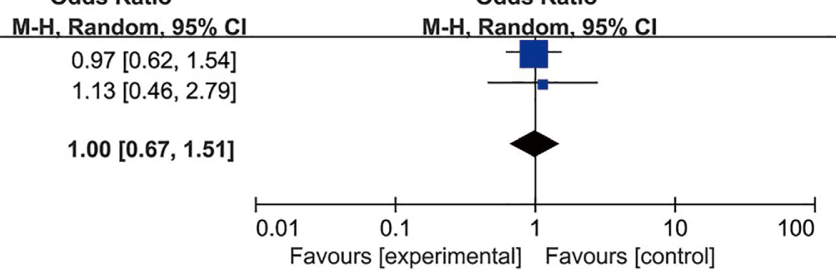

Figure 6 Meta-analysis of systemic adverse symptoms. (A) Nasopharyngitis, (B) headache, (C) upper respiratory tract infection, (D) pharyngitis.

is still a need for further in-depth study of the mechanisms of dapsone gel in the treatment of acne, its inhibitory effect on different kinds of acne, the antagonism of inflammatory cytokine expression, and the correlation with hormone secretion. The mechanisms of adverse events of dapsone treatment, as well as how to avoid the absorption of large doses of gel when used topically on large areas, are also important issues that need to be clarified in future research.

\section{Conclusions}

It is worth promoting the use of dapsone gel for the treatment of acne, and its efficacy and safety are excellent. However, more clinical and mechanistic studies must be conducted in various countries in order to support the continuing use of dapsone gel treatment in general clinical practice. 


\section{Acknowledgments}

Funding: None.

\section{Footnote}

Reporting Checklist: The authors have completed the PRISMA reporting checklist. Available at https://apm. amegroups.com/article/view/10.21037/apm-21-3935/rc

Conflicts of Interest: All authors have completed the ICMJE uniform disclosure form (available at https://apm. amegroups.com/article/view/10.21037/apm-21-3935/coif). The authors have no conflicts of interest to declare.

Ethical Statement: The authors are accountable for all aspects of the work in ensuring that questions related to the accuracy or integrity of any part of the work are appropriately investigated and resolved.

Open Access Statement: This is an Open Access article distributed in accordance with the Creative Commons Attribution-NonCommercial-NoDerivs 4.0 International License (CC BY-NC-ND 4.0), which permits the noncommercial replication and distribution of the article with the strict proviso that no changes or edits are made and the original work is properly cited (including links to both the formal publication through the relevant DOI and the license). See: https://creativecommons.org/licenses/by-nc-nd/4.0/.

\section{References}

1. Zhou M, Yang M, Zheng Y, et al. Skin surface lipidomics revealed the correlation between lipidomic profile and grade in adolescent acne. J Cosmet Dermatol 2020;19:3349-56.

2. Habeshian KA, Cohen BA. Current Issues in the Treatment of Acne Vulgaris. Pediatrics 2020;145:S225-30.

3. Poli F, Auffret N, Leccia MT, et al. Truncal acne, what do we know? J Eur Acad Dermatol Venereol 2020;34:2241-6.

4. Dréno B, Araviiskaia E, Kerob D, et al. Nonprescription acne vulgaris treatments: Their role in our treatment armamentarium-An international panel discussion. J Cosmet Dermatol 2020;19:2201-11.

5. Dessinioti C, Zouboulis CC, Bettoli V, et al. Comparison of guidelines and consensus articles on the management of patients with acne with oral isotretinoin. J Eur Acad
Dermatol Venereol 2020;34:2229-40.

6. Otlewska A, Baran W, Batycka-Baran A. Adverse events related to topical drug treatments for acne vulgaris. Expert Opin Drug Saf 2020;19:513-21.

7. Ghaoui N, Hanna E, Abbas O, et al. Update on the use of dapsone in dermatology. Int J Dermatol 2020;59:787-95.

8. Wolf R, Matz H, Orion E, et al. Dapsone. Dermatol Online J 2002;8:2.

9. Al-Salama ZT, Deeks ED. Dapsone 7.5\% Gel: A Review in Acne Vulgaris. Am J Clin Dermatol 2017;18:139-45.

10. Stotland M, Shalita AR, Kissling RF. Dapsone 5\% gel: a review of its efficacy and safety in the treatment of acne vulgaris. Am J Clin Dermatol 2009;10:221-7.

11. Tanghetti E, Dhawan S, Green L, et al. Clinical evidence for the role of a topical anti-inflammatory agent in comedonal acne: findings from a randomized study of dapsone gel $5 \%$ in combination with tazarotene cream $0.1 \%$ in patients with acne vulgaris. J Drugs Dermatol 2011;10:783-92.

12. Raimer S, Maloney JM, Bourcier M, et al. Efficacy and safety of dapsone gel $5 \%$ for the treatment of acne vulgaris in adolescents. Cutis 2008;81:171-8.

13. Stein Gold LF, Jarratt MT, Bucko AD, et al. Efficacy and Safety of Once-Daily Dapsone Gel, 7.5\% for Treatment of Adolescents and Adults With Acne Vulgaris: First of Two Identically Designed, Large, Multicenter, Randomized, Vehicle-controlled Trials. J Drugs Dermatol 2016;15:553-61.

14. Draelos ZD, Carter E, Maloney JM, et al. Two randomized studies demonstrate the efficacy and safety of dapsone gel, $5 \%$ for the treatment of acne vulgaris. J Am Acad Dermatol 2007;56:439.e1-10.

15. Tanghetti E, Harper JC, Oefelein MG. The efficacy and tolerability of dapsone $5 \%$ gel in female vs male patients with facial acne vulgaris: gender as a clinically relevant outcome variable. J Drugs Dermatol 2012;11:1417-21.

16. Eichenfield LF, Lain T, Frankel EH, et al. Efficacy and Safety of Once-Daily Dapsone Gel, 7.5\% for Treatment of Adolescents and Adults With Acne Vulgaris: Second of Two Identically Designed, Large, Multicenter, Randomized, Vehicle-Controlled Trials. J Drugs Dermatol 2016;15:962-9.

17. Faghihi G, Rakhshanpour M, Abtahi-Naeini B, et al. The efficacy of $5 \%$ dapsone gel plus oral isotretinoin versus oral isotretinoin alone in acne vulgaris: A randomized double-blind study. Adv Biomed Res 2014;3:177.

18. Marson JW, Baldwin HE. An Overview of Acne Therapy, Part 1: Topical therapy, Oral Antibiotics, Laser and Light 
Therapy, and Dietary Interventions. Dermatol Clin 2019;37:183-93.

19. Piette WW, Taylor S, Pariser D, et al. Hematologic safety of dapsone gel, $5 \%$, for topical treatment of acne vulgaris. Arch Dermatol 2008;144:1564-70.

Cite this article as: Wang X, Wang Z, Sun L, Liu H, Zhang F. Efficacy and safety of dapsone gel for acne: a systematic review and meta-analysis. Ann Palliat Med 2022;11(2):611-620. doi: 10.21037/apm-21-3935
20. Yale S, Stefanko N, McCarthy P, et al. Severe methemoglobinemia due to topical dapsone misuse in a teenage girl. Pediatr Dermatol 2020;37:377-8.

(English Language Editor: C. Betlazar-Mash) 